\title{
Integrate Study of a Bolivian Population Infected by Trypanosoma cruzi, the Agent of Chagas Disease
}

\section{Simone Frédérique Brenière ${ }^{+}$, Marie France Bosseno, François Noireau*, Nina Yacsik**;, Pascale Liegeard $*: *$, Christine Aznar ${ }^{* *: *}$, Mireille Hontebeyrie*:*:*}

\author{
Institut de Recherche pour le Développement (IRD), UR 08 Pathogénie des Trypanosomatidae, 911 Av. Agropolis, BP 5045, \\ 34032 Montpellier Cedex 1, France *Laboratório Nacional e Internacional de Referência em Taxonomia de Triatomíneos, \\ Departamento de Entomologia, Instituto Oswaldo Cruz-Fiocruz, Rio de Janeiro, RJ, Brasil **Instituto Boliviano de Biología de \\ Altura, La Paz, Bolivia ***Laboratoire d'Immunopathogenèse, Département d'Immunologie, Institut Pasteur, France \\ ****UFR de Médecine, Université des Antilles et de la Guadeloupe, Cayenne, Guyane Française
}

A cross section of a human population (501 individuals) selected at random, and living in a Bolivian community, highly endemic for Chagas disease, was investigated combining together clinical, parasitological and molecular approaches. Conventional serology and polymerase chain reaction $(P C R)$ indicated an active transmission of the infection, a high seroprevalence (43.3\%) ranging from around $12 \%$ in $<5$ years to $94.7 \%$ in $>45$ years, and a high sensitivity (83.8\%) and specificity of PCR. Abnormal ECG tracing was predominant in chagasic patients and was already present among individuals younger than 13 years. SAPA (shed acute phase antigen) recombinant protein and the synthetic peptide $R-13$ were used as antigens in ELISA tests. The reactivity of SAPA was strongly associated to Trypanosoma cruzi infection and independent of the age of the patients but was not suitable neither for universal serodiagnosis nor for discrimination of specific phases of Chagas infection. Anti-R-13 response was observed in $27.5 \%$ only in chagasic patients. Moreover, anti-R13 reactivity was associated with early infection and not to cardiac pathology. This result questioned previous studies, which considered the anti-R-13 response as a marker of chronic Chagas heart disease. The major clonets 20 and 39 (belonging to Trypanosoma cruzi I and T. cruzi II respectively) which circulate in equal proportions in vectors of the studied area, were identified in patients' blood by PCR. Clonet 39 was selected over clonet 20 in the circulation whatever the age of the patient. The only factor related to strain detected in patients' blood, was the anti-R-13 reactivity: $37 \%$ of the patients infected by clonet 39 (94 cases) had anti-R13 antibodies contrasting with only 6\% of the patients without clonet 39 (16 cases).

Key words: Chagas disease - recombinant proteins - polymerase chain reaction - clones - Bolivia

Chagas disease is an endemic infection affecting many Latin American countries. Bolivia is considered one of the most endemic countries. The endemic area covers $80 \%$ of the country and, in 1985 more than one million people were infected (WHO 1991). The vectorial transmission of Trypanosoma cruzi, the agent of the disease, is mainly assured by Triatoma infestans which presents a T. cruzi infection rate of around 30\% (WHO 1991). The vector control program is not yet expanded over all the country and, due to the large chagasic population, congenital transmission and transmission by blood transfusion are very abundant too (Azogue et al. 1985, Azogue \& Darras 1995). High seroprevalences reported in blood donors indicate the magnitude of the human infection even in the towns outside the endemic regions (Carrasco et al. 1990, Landivar et al. 1992). The rural population has been considered as the main population at risk of infection, however, it was recently shown that vectorial transmission is occurring in

This work was supported by a grant of World Health Organization Special Program for Research and Training in Tropical Disease (no. 910273).

${ }^{+}$Corresponding author. Fax: +33-4-6741.6330. E-mail: breniere@mpl.ird.fr

Received 27 April 2001

Accepted 9 October 2001 suburbs of the main cities too (Revollo et al. 1997, Albarracin-Veizaga et al. 1999). Moreover, cardiac morbidity as well as digestive alterations remain important (Weinke et al. 1988, Brenière et al. 1989, Pless et al. 1992).

Recent developments in molecular biology applied to Chagas disease proposed new tools for a better knowledge of the natural human infection. PCR is proposed for sensitive detection of parasites in human blood (Moser et al. 1989, Avila et al. 1993, Wincker et al. 1997, Russomando et al. 1998). Several recombinant proteins allow specific and sensitive detection of antibodies directed against $T$. cruzi . Recombinant proteins have been proposed as stage or pathological specific markers while others should be relevant for cure criteria (Affranchino et al. 1989, Levin et al. 1989, 1991, Mesri et al. 1990, Aznar et al. 1995, Gomes 1997, Guevara et al. 1997).

Genetic variability of $T$. cruzi is now well documented. This parasite is composed of natural clones which present high genetic differences and recent studies demonstrate the existence of two principal lineage; regarding the nomenclature, and in agreement between scientists, two groups are now named, T. cruzi I and T. cruzi II (Tibayrenc 1995, Luquetti et al. 1999). In Bolivia, two major distinct monophyletic groups of clones have been identified in the domestic cycle and, they belong to T. cruzi I and $T$. cruzi II respectively (Brenière et al. 1998). These groups named clonet 20 and 39 can be detected directly in blood 
by PCR and identified by hybridization with specific kDNA probes (Brenière et al. 1998).

We report here a transversal study of a cross section of an entire human population living in a highly endemic area in Bolivia (Cochabamba Department), selected at random, in order to determine the magnitude of the human infection combining together clinical, parasitological and molecular approaches including the determination of the T. cruzi clones. Each parameter was analyzed according to age and sex, and their relationships studied. The usefulness of each molecular tool was also examined and discussed.

\section{MATERIALS AND METHODS}

Studied area and patients - The 501 individuals examined were children, teenagers and adults all free of treatment and living in the village of Mizque (altitude 1,970 m) located in a highly endemic region for Chagas disease in Bolivia (Cochabamba Department). T. infestans was the only triatomine species collected in $100 \%$ of the dwellings and its T. cruzi infection rate was around $60 \%$. In this area, insect control program had been implemented after the study. The community had 3,850 inhabitants. Blood samples were collected during 1994 and 1995 and the age of the patients ranged from 1 to 83 years old. Children and teenagers were mainly from elementary school and college and a written consent was obtained from parents. The adults were volunteers, born and residents of Mizque. The study included 281 children from whom serological and parasitological results were previously reported (Wincker et al. 1997).

Interpretation of the ECG tracings - The electrocardiographic test (ECG) was applied among 232 individuals selected at random from the 501 studied including 123 chagasic patients. ECGs were recorded in 12 standard derivations using a portable Hewlett Packard electrocardiograph. Two physician doctors coded each tracing (without serological information of the cases) according to the classification previously proposed and discrepancies were resolved by mutual agreement (Maguire et al. 1982). The ECG's showing atrioventricular block (AVB), incomplete and complete right bundle branch block (IRBBB and CRBBB), left anterior hemiblock (LAH), multifocal ventricular extrasystole (MVE), or junctional rhythm (JR) were considered abnormal. The following abnormalities were considered as borderline: atrial extrasystole, junctional extrasystole, unifocal and non repetitive ventricular extrasystole, and $\mathrm{R}$ waves in left precordial leads without pattern of ventricular strain in adults $>35$ years old. The other tracings were considered as normal ECG.

Ig $G$ antibodies anti-T. cruzi - Specific anti-T. cruzi $\mathrm{IgG}$ 's were assessed in three assays except for five cases where only two tests were available. Immunofluorescence (IF) was performed at IBBA (Instituto Boliviano de Biología de Altura). Two ELISA assays were performed in two laboratories: IBBA (ELISA-IBBA) and Institut Pasteur Paris (ELISA-IP). The methodologies and the cut values of the three tests were previously described (Wincker et al. 1997, Aznar et al. 1997). ELISA values were expressed as ratio (optical density value of each sample/optical density value of cut value) for statistical analysis. The serological diag- nosis of Chagas infection was based on the positivity or negativity of at least two out of three tests.

Antibodies against SAPA recombinant protein - AntiSAPA antibodies were investigated among the total population (except 23 missing cases) using the fusion glutathion S-transferase/shed acute phase antigen (GST/SAPA) previously purified from T. cruzi (Ibañez et al. 1987, Smith \& Johnson 1988, Affranchino et al. 1989, Brenière et al. 1997). The current study included 266 sera from children previously tested and 212 additional ones from older patients (Brenière et al. 1997). Briefly, IgG antibodies were detected by ELISA, and SAPA optical density of each sample, was determined by the difference of values obtained by GSTSAPA-ELISA and GST-ELISA as control. The cut-off value for anti-SAPA was 0.38 (Brenière et al. 1997).

Antibodies against $R$-13 peptide - Sera from 469 individuals studied, selected at random, were tested twice for IgG anti-R-13 antibodies by ELISA (Aznar et al. 1995). In each test the samples were assayed in duplicate. The antigen was the synthetic peptide corresponding to the $\mathrm{C}$ terminal sequence (EEEDDDMGFGLFD) of T. cruzi ribosomal P-protein (Aznar et al. 1995). Cut-off values were calculated, in each protocol, as the mean optical density values obtained from 60 control sera $+2 \mathrm{SD}$. Control sera were represented by $40 \mathrm{~T}$. cruzi negative Bolivian sera and 20 sera from Caucasian individuals from a French blood bank.

PCR identification of clonet 20 and 39 - The recognition of clonet 20 and 39 was done by hybridization of the PCR products by clonet specific kDNA probes named 20 and 39 as previously described (Brenière et al. 1998). PCR was applied on 372 blood samples including 209 chagasic patients. Part of the sample was tested previously (Brenière et al. 1998).

Statistical tests - Statistics were computed by the Statix package. Prevalence rates of Chagas infection were calculated in different age classes and the correlation between prevalence and middle class age determined by the Pearson correlation test. $\chi^{2}$ test was used to compare distributions between several categories and $\chi^{2}$ Yates correction was applied when at least one of the expected values was $<5$. The non parametric test of Kruskal-Wallis was applied to compare average values obtained for two categories.

\section{RESULTS}

Chagas infection - Two hundred and seventeen individuals out of $501(43.3 \%)$ were positive in at least two of the three serological tests detecting total specific parasite $\mathrm{IgG}$ antibodies and were considered as chagasic patients. The accordance of the three tests was $94.7 \%$. Three young children with negative serology were also classified as chagasic: two with evidence of T. cruzi parasitaemia by buffy coat and 1 with positive PCR (Wincker et al. 1997). One adult patient with negative serology was also PCR positive. Finally, a total of 221 patients were classified as chagasic in this study (44.1\%). Chagas infection rates increased according to the age of patients from $11.8 \%$ to $94.7 \%$ (Table I, correlation coefficient $=0.93, p=10^{-4}$ ) and were not significantly different for male and female $(40 \%$ and $48.6 \%$, respectively; $\chi^{2}=3.29, \mathrm{df}=1, \mathrm{p}=0.07$ ). 
TABLE I

Age-specific prevalence rates of Chagas infection

\begin{tabular}{|c|c|c|c|c|c|c|c|c|c|c|c|c|}
\hline \multirow{2}{*}{$\begin{array}{l}\text { Age } \\
\text { (years) }\end{array}$} & \multicolumn{4}{|c|}{ Females } & \multicolumn{4}{|c|}{ Males } & \multicolumn{4}{|c|}{ Females and males } \\
\hline & $\mathrm{N}$ & $\mathrm{Ch}+$ & Ch- & $\% \mathrm{Ch}+$ & $\mathrm{N}$ & $\mathrm{Ch}+$ & Ch- & $\% \mathrm{Ch}+$ & $\mathrm{N}$ & $\mathrm{Ch}+$ & Ch- & $\% \mathrm{Ch}+$ \\
\hline $1-5$ & 17 & 3 & 14 & $17.6 \%$ & 17 & 1 & 16 & $5.9 \%$ & 34 & 4 & 30 & $11.8 \%$ \\
\hline $6-10$ & 70 & 34 & 36 & $48.6 \%$ & 150 & 63 & 87 & $42 \%$ & 220 & 97 & 123 & $44.1 \%$ \\
\hline $11-15$ & 62 & 27 & 35 & $43.5 \%$ & 66 & 18 & 48 & $27.3 \%$ & 128 & 45 & 83 & $35.2 \%$ \\
\hline $16-20$ & 21 & 7 & 14 & $33.3 \%$ & 17 & 10 & 7 & $58.8 \%$ & 38 & 17 & 21 & $44.7 \%$ \\
\hline $21-25$ & 4 & 1 & 3 & $25 \%$ & 4 & 2 & 2 & $50 \%$ & 8 & 3 & 5 & $37.5 \%$ \\
\hline $26-30$ & 5 & 3 & 2 & $60 \%$ & 9 & 6 & 3 & $66.7 \%$ & 14 & 9 & 5 & $64.3 \%$ \\
\hline $31-35$ & 9 & 8 & 1 & $88.9 \%$ & 3 & 1 & 2 & $33.3 \%$ & 12 & 9 & 3 & $75 \%$ \\
\hline $36-40$ & 7 & 5 & 2 & $71.4 \%$ & 6 & 3 & 3 & $50 \%$ & 13 & 8 & 5 & $61.5 \%$ \\
\hline $41-45$ & 6 & 5 & 1 & $83.3 \%$ & 0 & 0 & 0 & & 6 & 5 & 1 & $83.3 \%$ \\
\hline$>45$ & 11 & 10 & 1 & $90.9 \%$ & 8 & 8 & 0 & $100 \%$ & 19 & 18 & 1 & $94.7 \%$ \\
\hline Total & 212 & 103 & 109 & $48.6 \%$ & 280 & 112 & 168 & $40 \%$ & $492^{a}$ & 215 & 277 & $43.7 \%$ \\
\hline
\end{tabular}

$\mathrm{N}$ : patient number; $\mathrm{Ch}+$ : chagasic patient; $\mathrm{Ch}$-: no chagasic patient; $a$ : 9 cases had missing age data

Cardiac pathology - Table II summarized the characteristics of patients presenting abnormal ECG tracing (32 cases). The other 200 individuals had ECG tracing considered as normal. Among the 232 studied individuals, abnormal ECG was statistically associated with Chagas infection $\left(\chi^{2}=11.8, \mathrm{df}=1, p=0.0006\right)$ and this association was already present among individuals younger than 13 years $\left(\chi^{2}=5.41, \mathrm{df}=1, p=0.02\right)$ (not shown). Moreover, the prevalence of cardiac electric abnormalities was not significantly different among the following age groups: 13 to 18 years old, 19 to 35 years old and $>35$ years old groups $\left(\chi^{2}=0.38, \mathrm{df}=2, p=0.83\right)$. Only among adult patients ( $>25$ years old), ECG abnormalities were more common in men than in women (odd ratio $=4.4$ ). No differences of anti-T. cruzi antibodies rates were observed between patients with or without cardiac abnormalities: the Kruskal-Wallis non parametric test was applied to the ELISA-IBBA and ELISA-IP ( $p=0.55$ and $p=0.20$ respectively) and similarly for the IF test (titers $\leq 1 / 64$ versus titers $>1 / 64 ; \chi^{2}=3.3, \mathrm{df}=1, p=0.07$ ). The most frequent ECG alteration was LAH (61.5\% of patients) and the others were present in around $23-27 \%$. More than one alteration was observed among $42 \%$ of patients. Finally, $21 \%$ of chagasic patients presented an abnormal ECG ( 26 cases of 123).

Anti-SAPA IgG response - The mean ratio of optical density values were $1.8 \pm 1.14$ and $0.31 \pm 0.35$ for chagasic and non chagasic individuals respectively. Anti-SAPA antibodies were shown in $72 \%$ of chagasic patients and were significantly associated with $T$. cruzi infection $\left(\chi^{2}=\right.$ 236.4, $\left.\mathrm{df}=1, p<10^{-4}\right)$. Among chagasic patients, antiSAPA response was independent of $\operatorname{sex}\left(\chi^{2}=3.76, \mathrm{df}=1\right.$, $p=0.052)$ and ECG tracings $\left(\chi^{2}=0.01, \mathrm{df}=1, p=0.91\right)$. Moreover, similar optical density rates were observed for chagasic patients with abnormal and normal ECG $(1.84 \pm$ 1.18 and $1.62 \pm 1.06$ respectively; Kruskal-Wallis test, $p=$ 0.37 ; not shown). Table III showed that anti-SAPA response was more frequent among chagasic patients $<13$ years old than among older $\left(\chi^{2}=7.62, \mathrm{df}=1, p=0.005\right)$, but remained elevated among adult patients.
TABLE II

Chagas infection and ECG tracing of patients with abnormal ECG

\begin{tabular}{|c|c|c|c|c|c|}
\hline Code & Age & $\begin{array}{c}\text { Sexe } \\
\text { infection }\end{array}$ & Chagas & ECG tracing & $\begin{array}{c}\text { Interpretation } \\
\text { of ECG }{ }^{a}\end{array}$ \\
\hline Miz184 & 5 & $\mathrm{~F}$ & Yes & LAH & Abnormal \\
\hline Miz009 & 6 & M & No & LAH & Abnormal \\
\hline Miz099 & 6 & M & No & LAH, IRBBB & Abnormal \\
\hline Miz076 & 6 & M & Yes & LAH, IRBBB & Abnormal \\
\hline Miz042 & 7 & M & No & LAH & Abnormal \\
\hline Miz015 & 7 & M & Yes & LAH & Abnormal \\
\hline Miz020 & 7 & M & No & LAH & Abnormal \\
\hline Miz041 & 7 & $\mathrm{~F}$ & Yes & LAH & Abnormal \\
\hline Miz044 & 7 & M & Yes & LAH & Abnormal \\
\hline Miz103 & 7 & M & Yes & LAH, IRBBB & Abnormal \\
\hline Miz104 & 8 & M & Yes & IRBBB & Abnormal \\
\hline Miz018 & 9 & M & Yes & $\mathrm{LAH}$ & Abnormal \\
\hline Miz021 & $<10$ & $\mathrm{M}$ & Yes & LAH & Abnormal \\
\hline Miz454 & 12 & M & Yes & AVB & Abnormal \\
\hline Miz455 & 15 & M & Yes & AVB & Abnormal \\
\hline Miz413 & 15 & $\mathrm{~F}$ & Yes & LAH, SB & Abnormal \\
\hline Miz406 & 16 & $\mathrm{~F}$ & Yes & LAH, CRBBB, S & SB Abnormal \\
\hline Miz426 & $>18$ & $\mathrm{~F}$ & Yes & CRBBB & Abnormal \\
\hline Miz458 & 24 & $\mathrm{~F}$ & Yes & AVB & Abnormal \\
\hline Miz429 & 24 & M & Yes & LAH & Abnormal \\
\hline Miz467 & 29 & M & Yes & AVB & Abnormal \\
\hline Miz468 & 29 & $\mathrm{M}$ & Yes & AVB, SB & Abnormal \\
\hline Miz066 & 30 & $\mathrm{~F}$ & No & IRBBB, AVB & Abnormal \\
\hline Miz486 & 30 & M & Yes & LAH, SB & Abnormal \\
\hline Miz433 & 36 & M & Yes & CRBBB & Abnormal \\
\hline Miz445 & 39 & M & No & IRBBB & Abnormal \\
\hline Miz431 & 50 & $\mathrm{~F}$ & Yes & LAH, SB & Abnormal \\
\hline Miz506 & 56 & $\mathrm{~F}$ & Yes & $\mathrm{LAH}$ & Abnormal \\
\hline Miz446 & 57 & M & Yes & AVB & Abnormal \\
\hline Miz471 & 57 & M & Yes & LAH, SB & Abnormal \\
\hline Miz466 & 66 & M & Yes & AVB & Abnormal \\
\hline Miz485 & 67 & M & Yes & LAH & Abnormal \\
\hline
\end{tabular}

IRBBB: incomplete right bundle branch block; CRBBB: complete right bundle branch block; LAH: left anterior hemiblock; AVB: atriventricular block; SB:sinusal bradicardia; $a$ : classification according to Maguire et al. (1982) 
TABLE III

Anti-SAPA antibody response among chagasic patients of different age

\begin{tabular}{lccc}
\hline & \multicolumn{3}{c}{$\begin{array}{c}\text { Anti-SAPA response } \\
\text { Number of patients }\end{array}$} \\
\cline { 2 - 4 } Age (years) & $\mathrm{N}$ & Negative & Positive \\
\hline $1-6$ & 14 & 2 & $12(85.7 \%)$ \\
$7-12$ & 98 & 21 & $77(78.6 \%)$ \\
$13-18$ & 40 & 16 & $24(60 \%)$ \\
$19-35$ & 20 & 8 & $12(60 \%)$ \\
$>35$ & 29 & 10 & $19(65.5 \%)$ \\
\hline Total & 201 & 57 & $144(71.6 \%)$ \\
\hline
\end{tabular}

SAPA: shed acute phase antigen; $\mathrm{N}$ : patient number

Anti-R-13 IgG response - Twice ELISA assessed antiR-13 antibodies and the accordance between both assays was of $81.2 \%$. Individuals presenting disagreement were discarded from the analysis and finally, 381 individuals were included. Anti-R-13 antibodies were exclusively detected in chagasic patients (39 patients among 142 tested) demonstrating a strong association between anti-R-13 response and T. cruzi infection $\left(\chi^{2}=73.1, \mathrm{df}=1, p<10^{-4}\right)$. Anti-R-13 antibodies response among chagasic patients, was not related to ECG abnormalities $\left(\chi^{2}=0.98, \mathrm{df}=1, p=\right.$ $0.32)$ and $\operatorname{sex}\left(\chi^{2}=0.01, \mathrm{df}=1, p=0.93\right)$. Moreover, the anti-R-13 antibodies ratios were not different between the five chagasic patients with abnormal ECG (mean $=2.1 \pm$ 0.9 ) and the 12 patients with normal ECG (mean $=2.55 \pm$ 1.2 ), $p=0.53$, (Kruskal-Wallis test). Surprisingly, the percentage of chagasic patients with anti-R-13 antibodies was different according to the age (Table IV, $\chi^{2}$ Yates = $11.30, \mathrm{df}=4, p<0.05$ ). It is worth noting that more chagasic patients $<13$ years old $(41.4 \%)$ than older patients $>12$ years old $(17.4 \%)$ presented a positive response $\left(\chi^{2}=\right.$ $10.05, \mathrm{df}=1, p=0.0015)$. Furthermore, the antibody ratio was significantly increased among the younger popula-
TABLE IV

Age-specific prevalence of anti-R13 antibody response among chagasic patients

\begin{tabular}{crcc}
\hline & \multicolumn{3}{c}{$\begin{array}{c}\text { Anti-R13 response } \\
\text { Number of patients }\end{array}$} \\
\cline { 2 - 4 } Age (years) & $\mathrm{N}$ & Negative & Positive \\
\hline $1-6$ & 7 & 4 & $3(42.8 \%)$ \\
$7-12$ & 44 & 25 & $19(43.2 \%)$ \\
$13-18$ & 40 & 32 & $8(20 \%)$ \\
$19-35$ & 19 & 16 & $3(15.8 \%)$ \\
$>35$ & 27 & 23 & $4(14.8 \%)$ \\
\hline Total $^{a}$ & 137 & 100 & $37(27 \%)$
\end{tabular}

$a$ : two chagasic patients ( $<13$ years) with positive anti-R13 response were not included in table because their exact age is unknown.

tion $(<13$ years old, $\mathrm{m}=3.3 \pm 1.9 ;>12$ years old, $\mathrm{m}=2.3 \pm$ $1.4, p=0.009$, Kruskal-Wallis test).

Detection of clonet 20 and 39 in patient bloods - PCR detection of clonet 20 and 39 was applied among 372 individuals including 209 chagasic patients. PCR was positive (presence of $320 \mathrm{bp}$ amplified band) in $83.8 \%$ of chagasic patients, and its prevalence was independent of the ECG tracing $\left(\chi^{2}=1, \mathrm{df}=1, p=0.31\right)$ and $\operatorname{sex}\left(\chi^{2}=0.29\right.$, $\mathrm{df}=1, p=0.59)$. Higher percentage of positive PCR was observed in young patients $<13$ years than in older $\left(\chi^{2}=\right.$ $16.72, \mathrm{df}=1, p<10^{-4}$ ).

Table $\mathrm{V}$ summarized the hybridization results of positive PCR products (163 cases), and negatives ones (33 from randomly selected chagasic patients and 43 from non chagasic individuals as control) with probes 20 and 39, after their transfer on nylon membranes. Part of the sample (composed of 137 children < 10 years old) was previously tested, and the additional results confirmed the major prevalence of clonet 39 over clonet 20 in the blood of chagasic patients of any age in this population. Clonet 39 was detected in $77.8 \%$ of patients $>18$ years old and only $11.1 \%$ presented double infections with clonet 20 . Six PCR

TABLE V

Identification of clonets 20 and 39 of Trypansosoma cruzi by specific probes in PCR-amplified human bloods

\begin{tabular}{|c|c|c|c|c|c|c|c|c|c|}
\hline \multirow[b]{3}{*}{ Patients } & \multirow[b]{3}{*}{ Total no. } & \multicolumn{8}{|c|}{ Hybridization with } \\
\hline & & \multicolumn{2}{|c|}{ Probe 20 only } & \multicolumn{2}{|c|}{ Probe 39 only } & \multicolumn{2}{|c|}{ Probes $20 \& 39$} & \multicolumn{2}{|c|}{$\begin{array}{l}\text { Neither with } \\
\text { probe } 20 \text { nor } 39\end{array}$} \\
\hline & & No. & $\%$ & No. & $\%$ & No. & $\%$ & No. & $\%$ \\
\hline \multicolumn{10}{|l|}{ Chagasic patients with PCR + } \\
\hline Total & 160 & 4 & $2.5 \%$ & 109 & $68.1 \%$ & 26 & $16.3 \%$ & 21 & $13.1 \%$ \\
\hline $1-6$ years & 9 & 1 & $11.1 \%$ & 5 & $55.6 \%$ & 3 & $33.3 \%$ & 0 & $0 \%$ \\
\hline $7-12$ years & 84 & 1 & $1.2 \%$ & 57 & $67.9 \%$ & 14 & $16.7 \%$ & 12 & $14.3 \%$ \\
\hline $13-18$ years & 32 & 1 & $3.1 \%$ & 23 & $71.9 \%$ & 6 & $18.8 \%$ & 2 & $6.3 \%$ \\
\hline $19-35$ years & 13 & 1 & $7.7 \%$ & 11 & $84.6 \%$ & 1 & $7.7 \%$ & 0 & $0 \%$ \\
\hline$>35$ years & 22 & 0 & $0 \%$ & 13 & $59.1 \%$ & 2 & $9.1 \%$ & 7 & $31.8 \%$ \\
\hline \multicolumn{10}{|l|}{ Individuals with PCR - } \\
\hline Total & 76 & 0 & $0 \%$ & 5 & $6.6 \%$ & 1 & $1.3 \%$ & 70 & $92.1 \%$ \\
\hline Chagasic patients & 33 & 0 & $0 \%$ & 4 & $12.1 \%$ & 1 & $3 \%$ & 28 & $84.8 \%$ \\
\hline No chagasic individuals & 43 & 0 & $0 \%$ & 1 & $2.3 \%$ & 0 & $0 \%$ & 42 & $97.7 \%$ \\
\hline
\end{tabular}


negative samples presented a positive hybridization of the 320 bp band with probe 39 only (five cases) and with both probes (one case); all these patients had a positive serology except one (Table V). Moreover, no significant association of a particular clonet or mixed infection with ECG tracing or sex were observed. The anti-R13 response was analyzed according to the clonets detected in blood patients and significant differences were observed: $37 \%$ of the patients infected by clonet 39 (94 cases) had antiR13 antibodies contrasting with only $6 \%$ of the patients ( 16 cases) without clonet $39\left(\chi^{2}\right.$ Yates $=4.64, \mathrm{df}=1, p=$ $0.031)$.

\section{DISCUSSION}

In the present report we established the seroprevalence of $T$. cruzi infection among a population living in a Bolivian endemic region, in the village of Mizque (Cochabamba Department). Serodiagnosis was determined by three serological tests which presented high concordance even if different $T$. cruzi strains were used as source of antigens in the two ELISA tests and if the tests were processed independently in two different laboratories. Moreover, PCR confirmed the infection in around $84 \%$ of the seropositive patients. Positive PCR was found in 3 over 167 seronegative individuals among whom one presented circulating parasites. This patient, 8 years old, was probably in an early acute phase of infection, when the specific IgG response is not yet established. The two others cases may be considered as false positive PCR, but a singular situation has been previously described in Bolivia where cases of positive xenodiagnosis with negative serology were reported (Brenière et al. 1984). High sensitivity of PCR using kDNA primers has been demonstrated in different studies performed with Bolivian populations in endemic areas (Wincker et al. 1997, Antas et al. 1999). Seroprevalence increased regularly with the age of the patients as previously observed in a study of 140 individuals in a rural community of Cochabamba department (Pless et al. 1992). Taken together, these results show that $T$. cruzi active transmission occurs at any age in those rural endemic areas.

In the current study, chagasic patients were 3.8 times more likely to have had abnormal ECG tracing than non chagasic individuals. This strong association of conduction abnormalities and T. cruzi infection was also observed in two rural communities of Cochabamba and Santa Cruz departments. However, differences of cardiomyopathy prevalence were observed between the three studies, ranging from 10\% to 30\% (Weinke et al. 1988, Pless et al. 1992). Cardiomyopathy was first investigated among 131 adult chagasic patients originating from different Bolivian endemic areas and living in La Paz for at least 5 years (average time spend in La Paz: 10 years), where vectorial transmission is absent. Similar prevalence of cardiopathy was found among adults in Mizque population (23.5\%), showing a possible absence of relationships between endemicity and cardiomyopathy.

In Mizque, ECG abnormalities were also associated with seropositivity among young patients and its prevalence was not increased among older patients. This finding is not common, only one another study of Brazilian young patients mentioned this association (Andrade et al. 1998). This suggest a particular rapid development of pathology in such areas that may be due to the strain of parasite and prompt us to strongly recommend the treatment of young seropositive children. Men appeared more sensitive than women did to the development of cardiomyopathy measured by ECG abnormalities, in agreement with a previous study (Barretto et al. 1993). Moreover, in a wild rodent experimental model, results showed that gonadal hormones play a role in control of parasitemia (do Prado Junior et al. 1998). Nevertheless, data are not sufficient in humans to indicate a worse prognostics of Chagas disease associated with sex and influence of sex needs to be further investigated.

SAPA antigen response has been related to acute phase of Chagas disease when parasites are abundant in blood (Affranchino et al. 1989, Frasch \& Reyes 1990, Levin et al. 1991). The previous work in Mizque showed that anti-SAPA response was strongly associated with Chagas disease in young patients but not discriminative between initial and later stages of Chagas infection (Brenière et al. 1997). The current result showed that in older patients (> 13 years old) this response is still elevated $(60 \%)$ and this rate is maintained among 29 studied patients $>35$ years old $(65.5 \%)$. As the intracellular parasite multiplication has been proposed to induce high anti-SAPA antibody production, we compared the rates of these antibodies in patients with and without positive buffy coat test and PCR and no significant differences were found (data not shown). Higher SAPA reactivity was also recently suggested in symptomatic than in asymptomatic cases, but such association was not observed in Mizque sample (Lorca et al. 1992, 1993). These results and others definitively do not favor the common use of SAPA antigen for diagnosis of infection (lower sensitivity and specificity than conventional serology) neither for infection stage marker (among chronic patients 69\% present anti-SAPA antibodies). Nevertheless, SAPA molecule may be used to discriminate patients with $T$. cruzi and $T$. rangeli infections as proposed (Vergara et al. 1992, Saldana et al. 1995).

First results showed that anti-R-13 antibodies were absent in other protozoan infections such as leishmaniasis, African trypanosomiasis and malaria (Levitus et al. 1991). Moreover, anti-R-13 antibody response appeared related to the cardiac form of chronic Chagas disease (Levitus et al. 1991, Aznar et al. 1995). In the present sample anti-R-13 response was absent in non-chagasic population and its prevalence was not significantly different between asymptomatic patients and patients with ECG abnormalities (18.4\% and $29.4 \%$ respectively). Moreover, the anti-R13 reactivity was much lower than previously reported in chronic patients. A possible explanation of varying results is that the studied groups are not comparable. Most of the previously examined populations were selected in a clinical setting contrasting with the examination in this work of an entire population living in an endemic area selected at random. Mechanisms of pathogenicity of Chagas disease are not well understood and autoimmunity, including increased levels of autoantibodies, was considered to be involved (Kierszenbaum 1999). The production of autoantibodies against the human ribosomal $\mathrm{P}$ protein may well result from the mimicry between 
host protein and T. cruzi antigens. Furthermore, the observed discrepancies between the levels of anti-R-13 in different human populations may reflect strain genetic variability of this antigen, which has not been yet studied. The significant difference in anti-R-13 reactivity between patients infected by clonet 39 and patients where clonet 39 was not detected in blood, favors the hypothesis of strain dependence of the anti-R-13 antibodies production. Surprisingly, equal frequencies of anti-R-13 reactivity were observed in young and older patients, a result not yet described which indicates that autoimmune response should be involved early during the infection.

Previous results showed similar frequencies of clonet 20 and 39 in vectors collected in Mizque and these clonets were equally detected in blood patients during the acute phase (Brenière et al. 1998). The present results indicated that in later infection stages, clonet 39 is mainly detected in patients at any age. Indeed, clonets 20 and 39 belong to different groups of T. cruzi (T. cruzi I and T. cruzi II) which present high genetic distances between them (Brenière et al. 1998). These high genetic differences should be related to biological variability as virulence or variable susceptibility to the immune response (control of parasitemia) developed after the acute phase of human infection. Consequently, strain genetic differences may influence parasitemia in man. This important observation can explain discrepancies of PCR sensitivity between studies carried out in different endemic areas. In Bolivia and Brazil, in areas where $T$. cruzi II stocks are abundant, PCR technique presented high sensitivity contrasting with areas of Amazonian Basin and Mexico where only T. cruzi I stocks circulate (Wincker et al. 1994, 1997, Zingales et al. 1998, Pacheco et al. 1998).

\section{ACKNOWLEDGEMENTS}

To Fernando Vargas (Instituto Boliviano de Biología de Altura), José Luis Alcazar and Ramiro Fuentes (Cochabamba University) for technical assistance in field and laboratory. To Daniel Sanchez (Fundación Campomar, Buenos Aires) for providing the SAPA recombinant protein, and to Dr Gerardo Antezana (Instituto Boliviano de Biología de Altura, La Paz Bolivia) for revision of the electrocardiographic tracings.

\section{REFERENCES}

Affranchino JL, Ibañez CF, Luquetti AO, Rassi A, Reyes MB, Macina RA, Aslund I, Petterson U, Frasch ACC 1989. Identification of a Trypanosoma cruzi antigen that is shed during the acute phase of Chagas' disease. Mol Biochem Parasitol 34: 221-228.

Albarracin-Veizaga H, Carvalho ME, Nascimiento EM, Rodrigues VL, Casanova C, Barata JM 1999. Chagas disease in an area of recent occupation in Cochabamba Bolivia. Rev Saú Públ 33: 230-236.

Andrade AL, Zicker F, Rassi A, Rassi AG, Oliveira RM, Silva SA, de Andrade SS, Martelli CM 1998. Early electrocardiographic abnormalities in Trypanosoma cruzi-seropositive children. Am J Trop Med Hyg 59: 530-534.

Antas PR, Medrano-Mercado N, Torrico F, Ugarte-Fernandez R, Gomez F, Correa Oliveira R, Chaves AC, Romanha AJ, Araujo-Jorge TC 1999. Early, intermediate, and late acute stages in Chagas' disease: a study combining anti-galactose $\mathrm{IgG}$, specific serodiagnosis, and polymerase chain reaction analysis. Am J Trop Med Hyg 61: 308-314.
Avila HA, Pereira JB, Thieman O, Paiva E, Degrave W, Morel CM, Simpson L 1993. Detection of Trypanosoma cruzi in blood specimens of chronic chagasic patients by polymerase chain reaction amplification of kinetoplast minicircle DNA: comparison with serology and xenodiagnosis. J Clin Microbiol 31: 2421-2426.

Aznar C, Liegeard P, Mariette C, Lafon S, Levin MJ, Hontebeyrie M 1997. A simple Trypanosoma cruzi enzyme-linked immunoassay for control of human infection in nonendemic areas. FEMS Immunol Med Microbiol 18: 31-37.

Aznar C, Lopez-Bergami P, Brandariz S, Mariette C, Liegard P, do Carmo de Deus Alves M, Barreiro EL, Carrasco R, Lafon S, Kaplan D, Miguez H, Camacho C, Levitus G, Levin JM, Hontebeyrie M 1995. Prevalence of anti-R-13 antibodies in human Trypanosoma cruzi infection. FEMS Immunol Med Microbiol 12: 231-238.

Azogue E, Darras C 1995. Congenital Chagas in Bolivia: comparative study of the effectiveness and cost of diagnostic methods. Rev Soc Bras Med Trop 28: 39-43.

Azogue E, La Fuente C, Darras C 1985. Congenital Chagas'disease in Bolivia: epidemiological aspects and pathological findings. Trans R Soc Trop Med Hyg 79: 176-180.

Barretto AC, Arteaga E, Mady C, Ianni BM, Bellotti G, Pileggi F 1993. Male sex. Prognostic factor in Chagas' disease. Arq Bras Cardiol 60: 225-227.

Brenière SF, Bosseno MF, Telleria J, Bastrenta B, Yaksic N, Noireau F, Alcazar JL, Barnabé C, Wincker P, Tibayrenc M 1998. Different behavior of two Trypanosona cruzi major clones: transmission and circulation in Bolivian young patients. Exp Parasitol 89: 285-295.

Brenière SF, Carrasco R, Revollo S, Aparicio G, Desjeux P, Tibayrenc M 1989. Chagas' disease in Bolivia: clinical and epidemiological features and zymodeme variability of Trypanosoma cruzi strains isolated from patients. Am J Trop Med Hyg 41: 521-529.

Brenière F, Poch O, Selaès H, Tibayrenc M, Lemesre JL, Antezana G, Desjeux P 1984. Specific humoral depression in chronic patients infected with Trypanosoma cruzi. Rev Inst Med Trop São Paulo 26: 254-258.

Brenière SF, Yaksic N, Telleria J, Bosseno MF, Noireau F, Wincker P, Sanchez D 1997. Immune response to Trypanosoma cruzi shed acute phase antigen in children from an endemic area for Chagas' disease in Bolivia. Mem Inst Oswaldo Cruz 92: 503-507.

Carrasco R, Miguez H, Echalar L, Revollo S, Ampuerto T, Dedet JP 1990. Prevalence of Trypanosoma cruzi in blood banks of seven departments of Bolivia. Mem Inst Oswaldo Cruz 85: 69-73.

do Prado JC, Leal M de P, Anselmo-Franci JA, de Andrade HF, Kloetzel JK 1998. Influence of female gonadal hormones on the parasitemia of female Calomys callosus infected with the "Y" strain of Trypanosoma cruzi. Parasitol Res 84: 100105.

Frasch ACC, Reyes MB 1990. Diagnosis of Chagas' disease using recombinant DNA technology. Parasitol Today 5: 137139.

Gomes YG 1997. PCR and sero-diagnosis of chronic Chagas' disease. Biotechnological advances. Appl Biochem Biotechnol 66: 107-119.

Guevara AG, Taibi A, Billaut-Mulot O, Ouaissi A 1997. Trypanosoma cruzi: a 6 xhistidine-fused Tc24 protein useful for the serological diagnosis of Chagas' disease. Med Sc Research 25: 399-400.

Ibañez CF, Affranchino JL, Frasch ACC 1987. Antigenic determinants of Trypanosoma cruzi defined by cloning of para- 
site DNA. Mol Biochem Parasitol 25: 175-184.

Kierszenbaum F 1999. Chagas' disease and the autoimmunity hypothesis. Clin Microbiol Review 12: 210-223.

Landivar WH, Nakasa T, Tachibana H, Paz KC, Tateno S 1992. Seropositivity to Trypanosoma cruzi in blood donors in Santa Cruz, Bolivia. J Infect Dis 166: 1464-1465.

Levin MJ, Franco-da-Silveira J, Frasch ACC, Camargo ME, Lafon S, Degrave WN, Rangel-Aldao R 1991. Recombinant Trypanosoma cruzi antigens and Chagas' disease diagnosis: analysis of a workshop. FEMS Microbiol Immunol 89: 1120.

Levin MJ, Mesri E, Benarous R, Levitus G, Schijman A, LevyYeyati P, Chiale P, Ruiz A, Kahn A, Rosenbaum MB, Torres HN, Segura EL 1989. Identification of major Trypanosoma cruzi antigenic determinants in chronic Chagas' heart disease. Am J Trop Med Hyg 41: 530-539.

Levitus G, Hontebeyrie-Joskowicz M, Van Regenmorel MHV, Levin MJ 1991. Humoral autoimmune response to ribosomal P protein in chronic Chagas' disease. Clin Exp Immunol 85: 413-417.

Lorca M, Gonzalez A, Reyes V, Veloso C, Vergara U, Frasch C 1993. The diagnosis of chronic Chagas disease using recombinant antigens of Trypanosoma cruzi. Rev Med Chile 12: 363-368.

Lorca M, Gonzalez A, Veloso C, Reyes V, Vergara U 1992. Immnunodetection of antibodies in sera from symptomatic and asymptomatic Chilean Chagas' disease patients with Trypanosoma cruzi recombinant antigens. Am J Trop Med Hyg 46: 44-49.

Luquetti A, Prata A, Moncayo A, Romanha A, Jansen A, Zingales B, Morel C, Ponce C, Chiari E, Cupolillo E, Ponce E, Guhl F, Momen H, Coura JR, Steindel R, Miles M, Tibayrenc M, Fernandes O, Oliveira R, Zeledón R, Andrade S, Barrett T, Macedo V, Brener Z 1999. Recommendations from satellitte Meeting. Mem Inst Oswaldo Cruz (Suppl I): $1-6$.

Maguire JH, Mott KE, Hoff R, Guimaraes A, Franca JT, Almeida de Souza JA, Borges Ramos N, Sherlock IA 1982. A three-years follow-up study of infection with Trypanosoma cruzi and electrocardiographic abnormalities in a rural community in Northeast Brazil. Am J Trop Med Hyg 31: 42-47.

Mesri EA, Levitus G, Hontebeyrie-Joskowicz M, Dighiero G, Van Regenmortel MHV, Levin MJ 1990. Major Trypanosoma cruzi antigenic determinant in Chagas' heart disease shares homology with the systemic lupus erythematosus ribosomal P protein epitope. J Clin Microbiol 28: 12191224.

Moser DR, Kirchhoff LV, Donelson JE 1989. Detection of Trypanosoma cruzi by DNA amplification using polymerase chain reaction. J Clin Microbiol 27: 1477-1482.

Pacheco AD, Brenière SF, Bosseno MF, Espinoza B 1998. Estandardización de la técnica de reacción en cadena de la polimerasa (PCR), como prueba de diagnóstico en pacientes con la enfermedad de Chagas en el estado de Morelos. XII National Congress of Parasitology, Zacatecas, p. 10.

Pless M, Juranek D, Kozarsky P, Steurer F, Tapia G, Bermudez H 1992. The epidemiologiy of Chagas' disease in a hyperendemic area of Cochabamba, Bolivia: a clinical study including electrocardiography, seroreactivity to Trypanososoma cruzi, xenodiagnosis, and domiciliary triatomine distribution. Am J Trop Med Hyg 47: 539-546.

Revollo S, Garcia G, Ortiz R, Soto ML, Terrazas G, Postigo JR, Illanes M, Brenière SF, Bosseno M.F, Flores M 1997. Serodiagnóstico de la trypanosomiasis americana en una población infantil: análisis epidemiológico. Biofarbo V: 97 104.

Russomando G, Tomassone MMC, Guillen I, Acosta N, Vera N, Almiron M, Candia N, Calcena M, Figueredo A 1998. Treatment of congenital Chagas' disease diagnosed and followed up by the polymerase chain reaction. Am J Trop Med Hyg 59: 487-491.

Saldana A, Sousa OE, Orn A 1995. Immunoparasitological studies of Trypanosoma cruzi low virulence clones from Panama: humoral immune responses and antigenic cross-reactions with Trypanosoma rangeli in experimental infected mice. Scandinavian J Immunol 42: 644-650.

Smith DB, Johnson KS 1988. Single-step purification of polypeptides expressed in Escherichia coli as fusion with glutathione S transferase. Genetica 67: 31-40.

Tibayrenc M 1995. Population genetics of parasitic protozoa and other microorganisms. Adv Parasitol 36: 47-115.

Vergara U, Veloso C, Gonzalez A, Lorca M 1992. Evaluation of an enzyme-linked immunosorbent assay for the diagnosis of Chagas' disease using syntetic peptides. Am J Trop Med Hyg 46: 39-43.

Weinke TH, Ueberreiter K, Alexander M 1988. Cardiac morbidity due to Chagas' disease in rural community in Bolivia. Epidemiol Infect 101: 655-660.

Wincker P, Britto C, Borges Pereira J, Cardoso MA, Oeleman W, Morel CM 1994. Use of simplified polymerase chain reaction procedure to detect Trypanosoma cruzi in blood samples from chronic chagasic patients in a rural endemic area. Am J Trop Med Hyg 51: 771-777.

Wincker P, Telleria J, Bosseno MF, Cardoso MA, Marques P, Yaksic N, Aznar C, Liegeard P, Hontebeyrie M, Noireau F, Morel CM, Brenière SF 1997. PCR-based diagnosis for Chagas' disease in Bolivian children living in an active transmission area: comparison with conventional serology and parasitological diagnosis. Parasitology 114: 367-373.

WHO-World Health Organization 1991. Control of Chagas' Disease, Technical Report Series No. 811, WHO, Geneva.

Zingales B, Souto RP, Mangia RH, Lisboa CV, Campbell DA, Coura JR, Jansen A, Fernandes O 1998. Molecular epidemiology of American trypanosomiasis in Brazil based on dimorphisms of rRNA and mini-exon gene sequences. Inter J Parasitol 28: 105-112. 